\title{
TEMPOROMANDIBULAR JOINT PAIN SYN- DROME; EFFECT OF OCCLUSAL SPLINT THERAPY
}

\section{Dr. Uzma Awan', Dr. Nadeem Tariq ${ }^{2}$}

1. Assistant Professor Prothodontics Sharif Medical and Dental College, Lahore

MHPE student at UHS Lahore

2. Dental section

Punjab Medical College, Faisalabad.

Article received on:

13/08/2015

Accepted for publication:

$18 / 11 / 2015$

Received after proof reading:

$13 / 01 / 2016$

ABSTRACT... Introduction: The temporomandibular joint disorders TMD and their management is a problem in dentistry and complaints associated to this problem are pain in the area of joint and associated muscles along with limitations and clicking sounds during mandibular opening and closing. One of the popular method of treatment is splint therapy. Study design: It was longitudinal intervention study. Objectives: The purpose of this study is to assess about oral splint as an effective treatment for TMD patients. Period: Total study time for this study was about two years. Setting: Study was carried out in prosthodontics department of Sharif medical and dental college Lahore. Methodology: In the present study 40 patients were included the study. All patients were suffering from some psycho-social issue. Their maximum mouth opening MMO was measured and all of them were treated with occlusal splints. Results: There was significant improvement in $\mathrm{MMO}$ and reduction in pain.75\% patients responded to treatment very well, however, $22.5 \%$ responded moderately and $2.5 \%$ patients did not respond to treatment. Conclusion: Splint therapy is an effective way to treat TMD. Splint therapy along with some psychological rehabilitation of patients which may produce better results.

Key words: $\quad$ Splint therapy, TMD, MMO, bruxism, clicking sounds.

Article Citation: Awan U, Tariq N. Temporomandibular joint pain syndrome; effect of occlusal splint therapy. Professional Med J 2016;23(1):081-084. DOI: 10.17957/ TPMJ/16.3053

\section{INTRODUCTION}

The temporo mandibular joint disorders are a challenging problem in dental profession. Temporomandibular disorders (TMD) include a group of complaints presented by pain on joint area or in the temporomandibular joint (TMJ) or in the muscles of mastication. They also include deviations or limit in mandibular range of motion and TMJ clicking sounds and pain during opening and closing. ${ }^{1,2}$ The TMD have been reported to occur at rates of $40 \%$ of the general population, more common in women. ${ }^{3}$ Pain in the masticatory musculature and in joint during function is the most commonly reported symptom. While diagnosing the TMD patients, one must consider the psychological factor which can be one of the etiological factors producing and TMJ disorders. It was reported in 2008 that children and adults presented with bruxism, and who had personalities prone to anxiety, had more TMD signs and symptoms. ${ }^{4,5}$
The identified predictors for psychological distress can be financial stress, age between and 18 and 34 years-old, being female, and in a subsequent undergraduate year of their degree..$^{6,7}$

The treatments in literature are recommended for TMD are multiple. The other effective methods of treatment for relieving TMD pain are acupuncture, behavioural therapy, jaw exercises, postural training, and some pharmacological treatments. Evidence for the surgical treatment are also present in literature. ${ }^{8}$

Splint therapy for TMD management is noninvasive and one of the most popular treatment. Forty patients with acute symptoms of TMD were presented for over two years of time. All patients were treated with a flat plane occlusal stabilization splint. ${ }^{6,7}$ 
Fig-1. Michigan splint

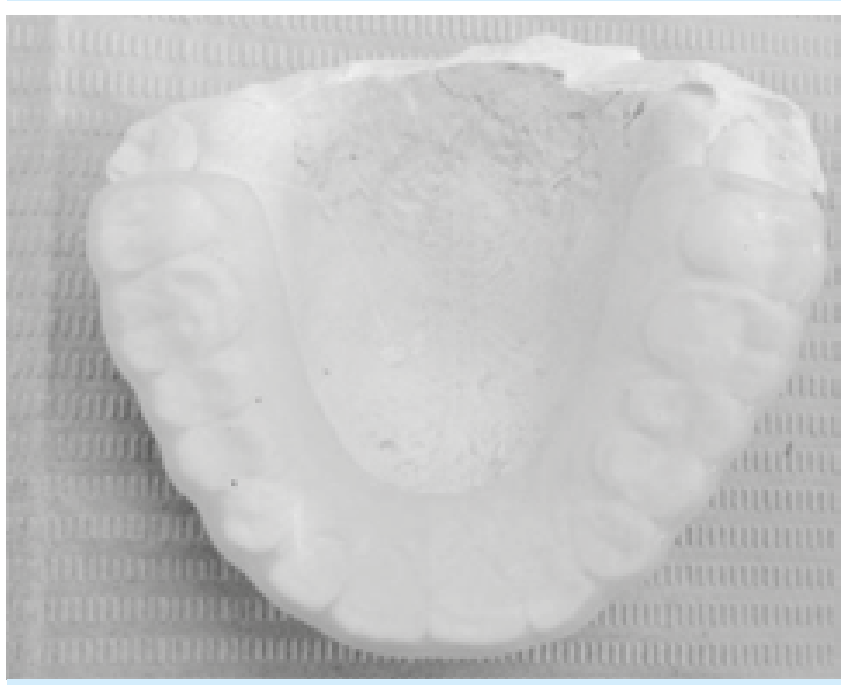

Fig-2. Michigan splint on cast

While history taking, it was revealed almost all the patients were suffering with acute anxiety. In this study, most of the patients were females suffering from family problems. Males who were suffering with TMD were students or having job related problems or financial problems. In present study eighty percent of patients were females and twenty percent of the patients were males and adequate time was given to the patient. While history taking, patients were listened to very well, so they could speak out their reason for anxiety. ${ }^{9}$

\section{MATERIAL AND METHODS}

It was longitudinal intervention study, carried out in prosthodontics department of Sharif medical and dental college Lahore.

Total 40 patients were included in this study and out of them $32(80 \%)$ were females and $8(20 \%)$ were males. All patients were suffering with acute temporomandibular joint pain. The mean age of patients was 27.325 years. All patients were treated with mandibular vacuum splint and analgesics.

\section{Inclusion criteria}

Patients presented with pain in TMJ area and difficulty for opening and closing jaw movements. The patients were excluded from study on the basis of diagnosis of rheumatoid arthritis, osteoarthritis, trauma to mandible or joint. History of ear infection and pain in ear since last one year were not included in this study.

Patients were clinically examined about MMO (maximum mouth opening) without pain, bilateral palpation of TMJ structures, including all masticatory muscles (masseter, temporalis, and posterior area of the jaw, submandibular region, lateral pterygoid area and the temporalis muscle) and joint area. A vernier calliper was used for measurement of mouth opening. ${ }^{10}$

Patients were examined every week to watch their progress for first three appointments and then afterwards, they were examined after every one month. On first appointment, ten patients were presented with severe pain and limited mouth opening $(>21 \mathrm{~mm})$ and nine patients presented with mild pain (simple descriptive pain intensity scale was used) ${ }^{11}$ in joint area and slight discomfort while mouth opening. Last group was of $(\leq 21)$ patients with moderate sign and symptoms, they presented with mouth opening < $21 \mathrm{~mm}$. These patients presented with slight to moderate pain during mouth opening, palpation and mastication. Mouth opening was measured on first appointment, second appointment and last appointment and all patients were given stabilization splint. ${ }^{12,3}$

\section{RESULTS}

Total 40 patients $(n=40)$.Age varies from 10- 42 years. And average age equals to 27.325 years. Females were an $80 \%$ and males were at $20 \%$. $75 \%$ patients responded to the treatment very well irrespective of gender and $22.5 \%$ patients responded to splint therapy moderately. $2.5 \%$ patients did not respond to treatment. The 
study is based on six appointments. Mean mouth opening on first appointment was $34 \mathrm{~mm}$ (Min.18mm max.50mm). Mean improved on next appointment, it was $36.9 \mathrm{~mm}$ (min.20mm max. $52 \mathrm{~mm}$ ). And when it was measured on last appointment it jumped up to $39 \mathrm{~mm}$ (min.22mm max52mm). as illustrated in fig.3.

\begin{tabular}{|c|c|}
\hline Appointments & Mean MMO and standard deviation \\
\hline $1^{\text {st }}$ appointment & $34.0 \mathrm{~mm}$ SD 12.05 \\
\hline $2^{\text {nd }}$ appointment & $36.9 \mathrm{~mm}$ SD 10.69 \\
\hline Last appointment & $39.0 \mathrm{~mm}$ SD 8.72 \\
\hline $\begin{array}{c}\text { Table-I. Showing improvement in maximum mouth } \\
\text { opening from } \text { 1 }^{\text {st }}, \text { 2 }^{\text {nd }} \text { and last appointment with } \\
\text { standard deviation. }\end{array}$ \\
\hline
\end{tabular}

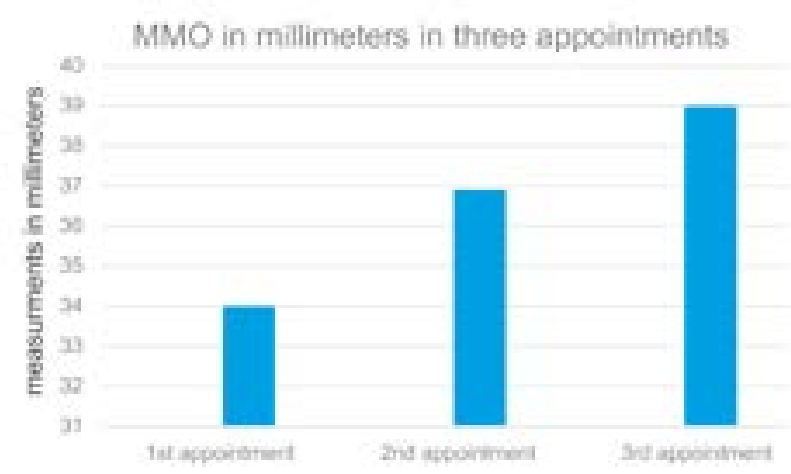

Fig-3. Illustrating improvement in MMO (maximum mouth opening)

First three appointments were after one week and rest of the three appointments were after every one month. Thirty patients (75\%) out of forty showed significant improvement in pain and MMO till sixth appointment. Nine patients (22.5\%) show moderate improvement in pain but mouth opening was increased. One patient $(2.5 \%)$ did not respond to treatment.

SPSS version 20 was used to analyze the results. As illustrated in fig. 4.

\section{DISCUSSION}

TMD is usually a painful condition for the joint and for muscles related to this joint. ${ }^{1}$

\section{Responses of the patients to the treatment}

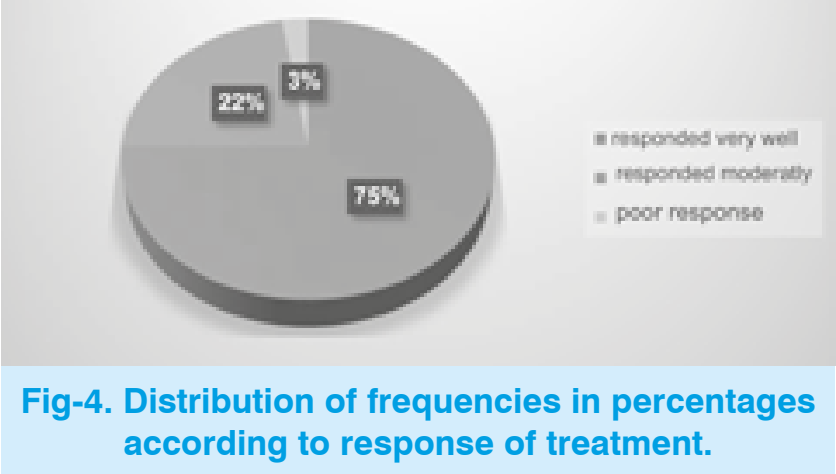

A Lot of treatments for example occlusal appliances, acupuncture, behavioral therapy, jaw exercises, postural training, and some pharmacological treatments, surgery is suggested for management of TMD. ${ }^{8}$ The most common is oral splint therapy, in which, splints are made to cover the maxillary or mandibular teeth. These splints can be made up of hard or soft material. Their basic function is to stabilize the occlusion ${ }^{12,13}$

The most common type of occlusal splint used to treat TMD is Michigan splint,(fig.1,2) a flat plane splint which supports both side of teeth.These type of splints relief the joint by disarticulating the teeth and increasing the vertical dimension of occlusion. As a result, in the joint, there will be a reduced synovitis and masticatory muscle activity. These type of occlusal splints may also change condylar position in glenoid fossa and may also change in the existing occlusal relationship resulting in reduction of abnormal muscle activity and spasm. ${ }^{13}$

Occlusal splint could eradicate or improve the signs and symptoms of TMD patients presented with pain and limited mouth opening.

This study has certain limitations that should be considered. The first is the size and the heterogeneity of the sample, a larger sample and long duration would probably bring up more conclusive results regarding TMD treatment. There are studies in which they found positive 
relationship between TMD and psychological factors, higher levels of anxiety and depression should lead to a lower MMO.

\section{CONCLUSION}

Non-invasive TMJ disorders treatment approaches are effective treatment but every patient in this study was suffering from some psychological and emotional issues (anxious, depressive, stress) so they needed some sort of mixed approach. Treatment including dental and psychological approaches at the same time appears to have more effective and may produce better results.

Copyright(C) 18 Nov, 2015.

\section{REFERENCES}

1. Okeson J. Current terminology and diagnostic classification schemes. Oral Surgery, Oral Medicine, Oral Pathology, Oral Radiology, and Endodontology. 1997;83(1):61-64.

2. Auerbach S, Laskin D, Frantsve L, Orr T. Depression, pain, exposure to stressful life events, and longterm outcomes in temporomandibular disorder patients. Journal of Oral and Maxillofacial Surgery. 2001;59(6):628-633.

3. Symptoms of temporomandibular disorders in the population: an epidemiological study. $\mathrm{j}$ orofac pain. 2010;3(24):270-8.

4. Restrepo C, Vsquez L, Alvarez M, Valencia I. Personality traits and temporomandibular disorders in a group of children with bruxing behaviour. Journal of Oral Rehabilitation. 2008;35(8):585-593.

5. Pergamalian A, Rudy T, Zaki H, Greco C. The association between wear facets, bruxism, and severity of facial pain in patients with temporomandibular disorders. The Journal of Prosthetic Dentistry. 2003;90(2):194-200.

6. Auerbach S, Laskin D, Frantsve L, Orr T. Depression, pain, exposure to stressful life events, and longterm outcomes in temporomandibular disorder patients. Journal of Oral and Maxillofacial Surgery. 2001;59(6):628-633.

7. Gameiro G, da Silva Andrade A, Nouer D, Ferraz de Arruda Veiga M. How may stressful experiences contribute to the development of etemporomandibular disorders? Clin Oral Invest. 2006;10(4):261-268.

8. LIST T, AXELSSON S. Management of TMD: evidence from systematic reviews and meta-analyses. Journal of Oral Rehabilitation. 2010;37(6):430-451.

9. Ridd M, Shaw A, Lewis G, Salisbury C. The patient âe“ doctor relationship: a synthesis of the qualitative literature on patients' perspectives. British Journal of General Practice. 2009;59(561):116-133.

10. CALIXTRE L, Grãœninger B, CHAVES T, OLIVEIRA A. Is there an association between anxiety/depression and temporomandibular disorders in college students? J Appl Oral Sci. 2014;

11. [Internet]. 2015 [cited 18 October 2015]. Available from: http://ftp://ftp.hrsa.gov/hab/F4-2.pdf.

12. Al-Ani Z, Gray R, Davies S, Sloan P, Glenny A. Stabilization Splint Therapy for the Treatment of Temporomandibular Myofascial Pain: A Systematic Review. Journal of Dental Education [Internet]. 2005 [cited 8 July 2015];69(11):1242-1250. Available from: http://www.jdentaled.org/content/69/11/1242.long.

13. Rahul Srivastava P. Oral splint for temporomandibular joint disorders with revolutionary fluid system. Dental Research Journal [Internet]. 2013 [cited 8 July 2015];10(3):307. Available from: http://www.ncbi.nlm. nih.gov/pmc/articles/PMC3760352/.

\section{PREVIOUS RELATED STUDY}

Ehsan Rathore, Altaf Hussain Rathore. TEMPOROMANDIBULAR JOINT ANKYLOSIS (Review) Prof Med Jour 18(4) 542-546 Oct, Nov, Dec 2011.

\section{AUTHORSHIP AND CONTRIBUTION DECLARATION}

\begin{tabular}{|c|l|l|l|}
\hline Sr. \# & \multicolumn{1}{|c|}{ Author-s Full Name } & \multicolumn{1}{|c|}{ Contribution to the paper } & Author=s Signature \\
\hline 1 & Dr. Uzma Awan & 1st Author & \\
2 & Dr. Nadeem Tariq & 2nd Author & \\
\hline
\end{tabular}

